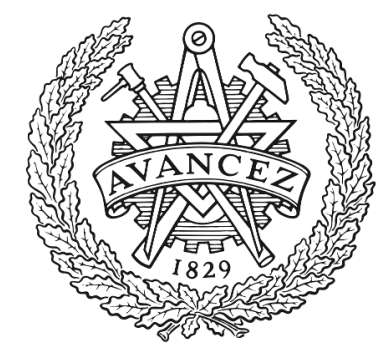

\title{
CHALMERS
}

UNIVERSITY OF TECHNOLOGY

\section{Combining Industrial Symbiosis with Sustainable Supply Chain Management for Development of Urban Communities}

Downloaded from: https://research.chalmers.se, 2023-04-26 11:04 UTC

Citation for the original published paper (version of record):

Rosado, L., Kalmykova, Y. (2019). Combining Industrial Symbiosis with Sustainable Supply Chain Management for Development of Urban Communities. IEEE Engineering Management Review, 47(2): 103-114.

http://dx.doi.org/10.1109/EMR.2019.2911060

N.B. When citing this work, cite the original published paper.

C2019 IEEE. Personal use of this material is permitted.

However, permission to reprint/republish this material for advertising or promotional purposes 


\title{
Combining Industrial Symbiosis with Sustainable Supply Chain Management for Development of Urban Communities
}

\author{
Leonardo Rosado* and Yuliya Kalmykova ${ }^{1}$ \\ *Corresponding author, PhD, Associate Professor, Department of Architecture and Civil \\ Engineering, Chalmers University of Technology, 412 96, Gothenburg, Sweden; Tel.: +46-(0)31 \\ 772 2154, E-mail: rosado@chalmers.se \\ ${ }^{1} \mathrm{PhD}$, Associate Professor, Department of Architecture and Civil Engineering, Chalmers \\ University of Technology, 412 96, Gothenburg, Sweden
}

Keywords: Sustainable supply chain management, circular economy, industrial symbiosis, community economic development, urban planning, green supply chain management

\begin{abstract}
Growing urban population is putting pressure on the supply of natural resources leading to global environmental impacts and calling for new ways to manage urban development. Circular economy strategies can provide the means to both increase resource productivity and generate new business opportunities. Industrial symbiosis is one such strategy. We explore an industrial symbiosis application in this article. While most previous industrial symbiosis applications has been limited to eco-industrial parks, here we propose an adaptation of the industrial symbiosis and sustainable supply chain management concepts to urban areas in general. It is a way to develop economic clusters incorporating symbiotic links between multiple products supply chains. A proposed iterative facilitated industrial symbiosis method identifies an economic cluster focus, stakeholders, opportunities for resource exchange and sharing of infrastructure, as well as other important elements. The method provides systematic guidance for practitioners seeking ways to grow local industry and economy, increase resource productivity, reduce wastes, and better utilize local resources. Benefits of industrial symbiosis and barriers to its implementation are also identified in the method. The method comprises 5 phases, each illustrated on an example drawn from our application of the method in an urban development in Gothenburg, a city in Sweden.
\end{abstract}

\section{Introduction}

Population growth in urban areas, with 2.5 billion more people expected to live in cities by 2050 (UN, 2014), is putting pressure on the supply of natural resources. This situation is leading to increased resource scarcity and global environmental impacts. It also affects the economy with price inflation (UNEP 2012).

The circular economy (CE) is one approach that may help to solve this challenge by increasing resource productivity while also simultaneously stimulating economic growth and creating more job opportunities. It has been estimated that shift to CE by 2030 would increase resource productivity by 30\%, deliver GDP increases by $1 \%$ and create 2 million additional jobs (EC, 2014).

CE measures as eco-design and waste prevention are estimated to bring EUR 600 billion net 
savings for European Union (EU) businesses. It is expected to also reduce greenhouse gas emissions. Recently, a global agenda for CE has been suggested (Geng et. al., 2018). Although the $\mathrm{CE}$ concept has not yet been consolidated, discussions on common definition and methodology for implementation are ongoing. Examples of CE application exist for industrial parks, different goods flows, product supply chains and selected materials and substances (Kalmykova et al., 2018).

More experience needs to be developed in CE implementation for a range of geographic scales including urban, regional, national and global scales. In this paper we introduce a method for CE implementation suitable for urban and regional scales. The method builds upon the idea of economic clusters formation, providing a range of benefits for the involved organizations and for the region where they operate (Martin and Sunley, 2003; St. John and Pouder, 2006).

The clusters, which are agglomerations of interlinked businesses and institutions, were shown to confer an economic advantage to its participants through external economies of scale and networking (Deutz and Gibbs 2008). External economies of scale arise from sharing factors of production, value chains and supporting institutions (Bathelt 2005, Deutz and Gibbs 2008). Networking leads to exchange in tacit knowledge and trust formation among companies and organizations (Morgan 2004). The cluster development concept has attracted particular interest of policy-makers concerned with urban development (Cumbers and Mackinnon, 2004).

The novelty of our approach is in combining industrial symbiosis (IS) with sustainable supply chain management (SSCM) concepts for CE implementation. In IS, diverse organizations are engaged with the aim of reducing resource use, by sharing resources, using wastes for secondary raw materials and fostering eco-innovation (Lombardi and Laybourn, 2012). While previously applied only to eco-industrial parks, recent IS applications are no longer limited by geographical colocation. There are multiple mechanisms to connect partners and develop mutually beneficial relationships (Lombardi and Laybourn, 2012).

Focusing on technological development of resource sharing and on interorganisational relations development, IS does not explicitly consider the social dimension of sustainability. When using the sustainable supply chain (SSC) term, the default perspective is an environmental sustainability. However, inclusion of other dimensions of corporate social responsibility in SSC is occurring (Sarkis, 2012). Because urban development should consider all three pillars of sustainability, social, environmental and economic, we use the following SSCM definition: "the strategic, transparent integration and achievement of an organization's social, environmental, and economic goals in the systemic coordination of key interorganizational business processes for improving the long-term economic performance of the individual company and its supply chains” (Carter and Rodgers, 2008).

IS and SSCM can be applied to CE development because they aspire to the CE goal of improving sustainability of resource use. Both concepts deal with interorganizational relationships based on material and energy flows and also share the approach of closing material loops. Yet, despite the common ground, the cross-pollination between the two concepts is still new (Liu et. al. 2018).

The rare published studies aspiring to IS integration in SSCM have encouraged interorganisational relationships amongst enterprises through a single supply chain (Leight and Li 2015). Alternative, it has been shown that resource pathways, and therefore opportunities for IS, increase with the 
diversity of industries (Jensen, 2016). Therefore we propose a new method that combines industrial symbiosis and SSCM by integrating multiple supply chains of different products through finding possible by-product exchanges and identifying infrastructures that can be shared to gain economies of scale. The method uses a facilitated industrial symbiosis framework (Paquin and HowardGrenville, 2012). After outlining the method, we also exemplify its application in a case-study.

\section{Background and Method}

The proposed facilitated IS method builds upon a closed loop supply chain (CLSC) that is a key principle shared by circular economy, industrial symbiosis and SSCM. CLSC stages include sourcing, production, logistics, consumption and end-of-life (EOL) (Figure 1).

Unlike traditional forward supply chains that concludes with customer consumption, CLSC includes return processes to capture additional value. These return processes also enable environmental benefits in supply chain stages from raw material extraction to final disposal of the product. The return processes that loop the supply chain are: acquiring products from end-users; reverse logistics to move the products from location of use to point of disposition; testing, sorting and disposition to assess products condition for effective re-use; direct reuse, repair, remanufacture, recycle, disposal or energy recovery; and re-marketing to sell and distribute repaired products (Guide et.al, 2003).

Once CLSC for different products are defined, possible interactions between supply chains can be explored to uncover IS opportunities (Figure 2). The objective of the method is to maximize symbiosis through linkages among the chains.

Possible CLSC interactions are (Figure 2):

Interactions by resource exchange occurs when output resources of one CLSC serves as an input for another.

Interactions by sharing infrastructure. Infrastructure may include plant, equipment and services like heat, electricity, distribution and waste treatment. In Figure 2, sharing infrastructure is depicted by a two headed arrow connecting the logistics stages in supply chains A and B.

Interactions by own resources occurs when a by-product is used as raw material within the same supply chain. In Figure 2, by-product from production is used in the sourcing inside supply chain $\mathrm{B}$ to produce the same type of product.

In practice, details of supply chains and possible interactions between them are defined using a facilitated IS framework that includes organized involvement of stakeholders. Figure 3 presents the developed IS formation facilitation method, which includes 5 phases: preparation; identification of the focus for a potential cluster (Focus); engagement with stakeholders; synthesis of information and addition of new links to the cluster (Development); and consolidation of supply chains and stakeholders in the cluster (Consolidation). 


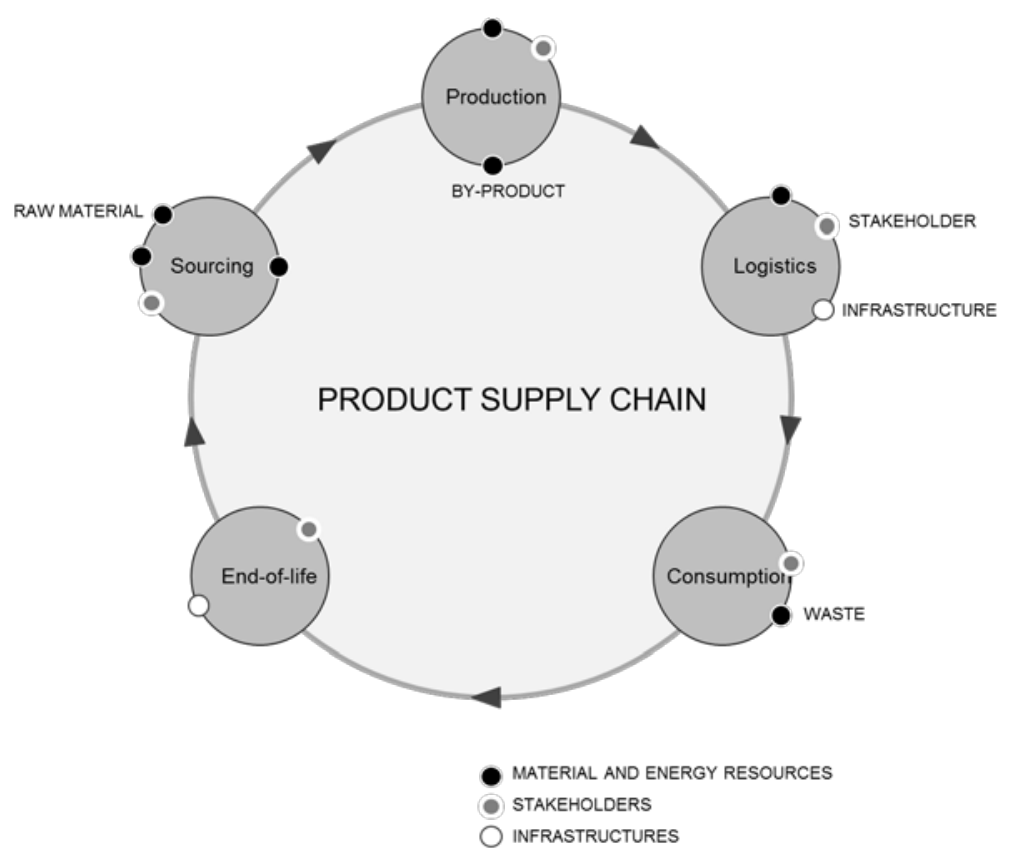

Figure1. Closed loop supply chain

In the preparation phase, characteristics and development objectives, such as economic, environmental or social goals, for a local community are identified; the relevant for cluster economic sectors and stakeholders are also identified.

The information is obtained from literature research and local authorities. Also, databases of typical resource consumption and waste generation categorized by industries, and of possible waste exchanges are being developed to assist in identifying potential symbioses (Patricio et.al. 2019).

In the following phase, the focus for potential cluster is defined, where the drivers, relevant supply chains and their stages are identified, and a list of existing infrastructures and stakeholders is made in consultation with local authorities. The next phase involves engaging with the identified stakeholders using a workshop format. The first workshop is conducted in order to assess their interests and characterize their activities, along with equipment, infrastructures, materials and goods used. Special focus is given to identification of specific barriers and requirements, such as certification processes. Examples of stakeholders include municipal and local administrative offices, large, medium and small-size companies, and non-governmental organizations (NGO). Enterprises are organized in stages of closed loop supply chains.

In the development phase, information is gathered, stakeholders, resources and infrastructures are mapped and a list of requirements and barriers is created. Additional potential stakeholders and possible symbioses between stages of the various CLSCs are identified. The following information is collected for each supply chain:

Sourcing: the goods needed during production and the involved stakeholders;

Production: products and by-products occurring during the production process; 
Logistics: the management processes that occur to the product until it reaches the final consumer or to be used as an intermediate product are identified. This may include additional processing such as refrigeration and storage. Also, stakeholders and used resources are identified;

Consumption: possible customers, final consumption of the product by customers; and

End-of-life: products after consumption, wastes, necessary infrastructures and stakeholders.

The next set of stakeholders that should be brought to the discussion is identified. This leads to a second workshop, which involves a larger set of stakeholders. In this consolidation phase, CLSCs for different products are derived and varied interactions are explored among the supply chains (Figure 2).

The objectives are to maintain closed individual supply chains while maximizing the opportunities for resource and energy efficiency through inter-linkages. The designed IS scheme can now be used as a basis for community development and as a starting point in industrial symbiosis implementation. Iterating through the method's central loop (Figure 3) consisting of the focus, engagement, development and consolidation phases, provides a systemic way to increase symbiotic linkages. 


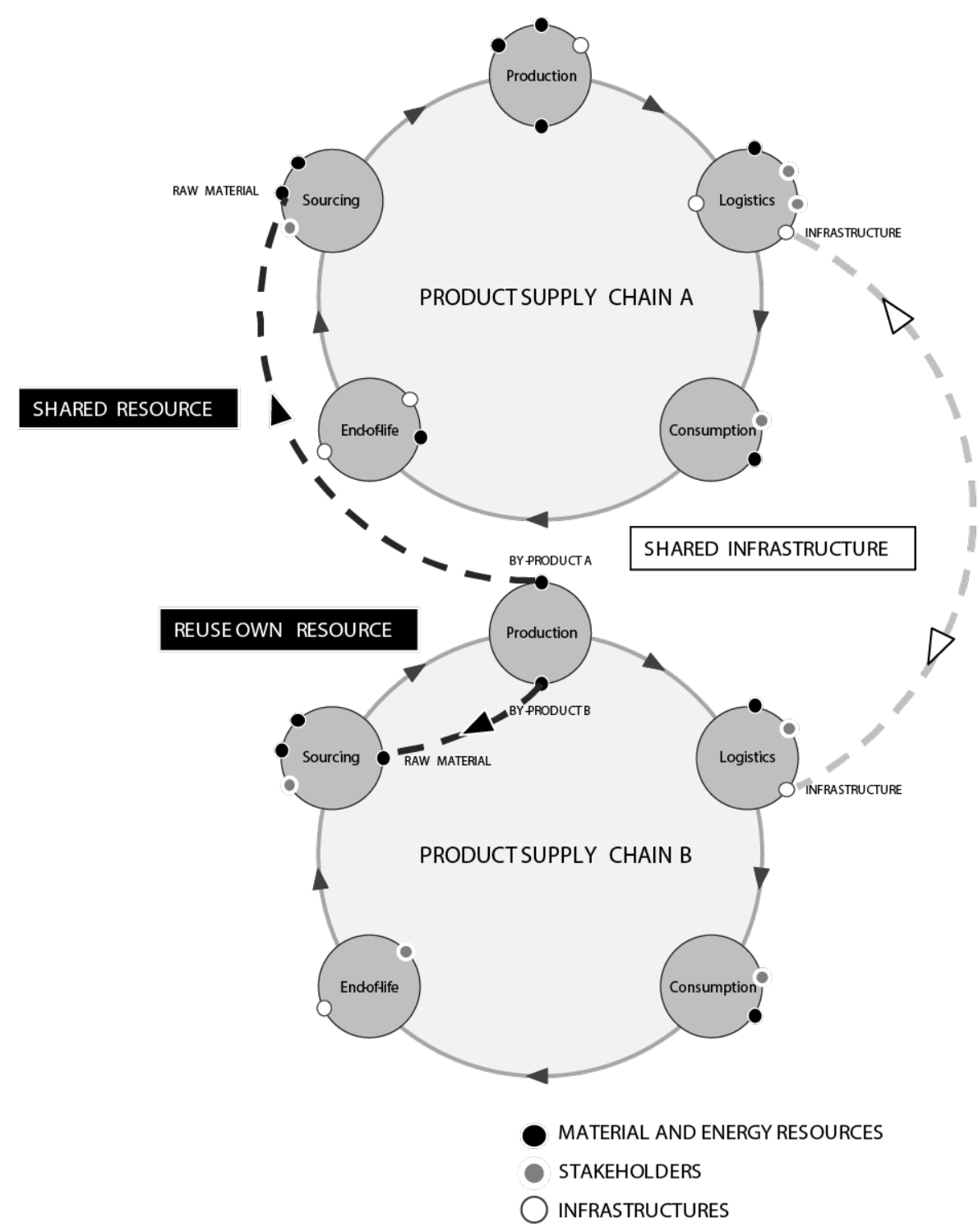

Figure 2. Interacting closed loop supply chains

\section{Case study: Building an urban food production cluster in Gothenburg}

A case study for two districts in the northeast Gothenburg (Sweden) was used to test and apply the proposed facilitated method for IS and SSCM integration. The two district region comprises a fourth of the municipality's area and $20 \%(90,000)$ of its population. This part of Gothenburg is characterized by high unemployment.

It is known that a significant proportion of the population (around 75\%), are represented by migrant mainly originating in foreign countries. This population has skills in farming and food production 
that have not been utilized. The geographical area of the study has a large and suitable for agriculture open land and rich natural resources.

The Utveckling Nordost (UNO) municipal company, tasked by the city with promotion of economic development of northeast Gothenburg, has provided a platform for the facilitated industrial symbiosis method in this area; they also provide feedback regarding the method.

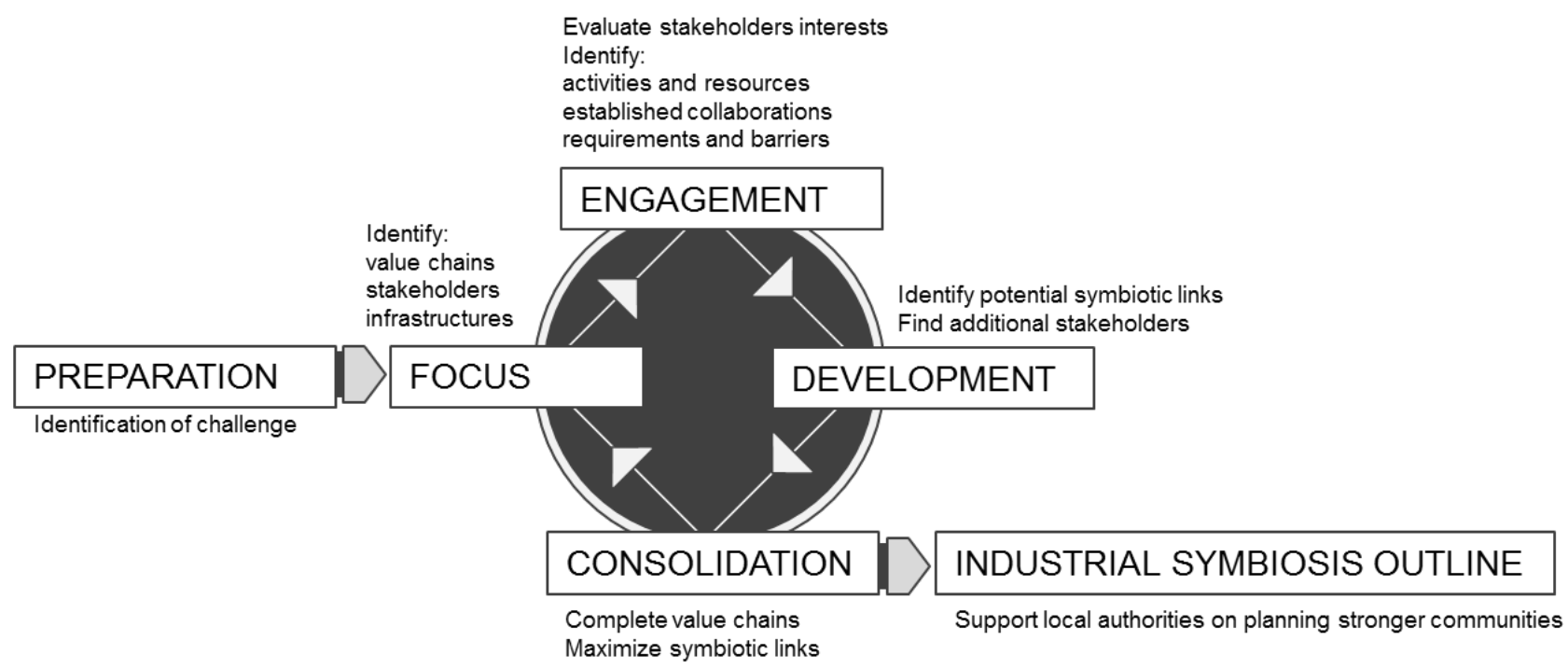

Figure 3. Facilitated industrial symbiosis method for developing local communities

\subsection{Phases 1 and 2 -- Preparation and establishing the main focus of the cluster}

In the preparation phase, the potential cluster around a network of local food production is derived with the following main development objectives for the area (according to UNO):

- increase the production and end market for locally produced food products;

- strengthen the network of small-scale producers; and

- bridge the gaps between cities and suburbs.

Information from UNO and other local authorities was gathered to prepare for engagement with stakeholders from the production sector. Results from relevant previous studies were analyzed, such as UNO's pre-study containing mapped resources and skills in urban farming and food production in the area (Melander 2013).

Possible contributions to other local goals were taken into account, such as the Gothenburg municipality goal to reduce the carbon footprint of their operations, including lower emissions associated with the food being served in schools, pre-schools and elderly homes (Environmental and Climate Committee, 2014). The information served as a basis for outlining, jointly with UNO, the key stakeholders and opportunities for IS cooperation in the area. The drivers and barriers that might exist were identified. 
Potential synergies between different local actors, connected to food production, distribution and sales, as well as food tourism were established. Waste generation in different stages of the product chains was also discussed. The key stakeholders served as the starting point for determining the products supply chains. Four supply chains were identified: lamb, beef, chicken, and fruits and vegetables (Figure 4).

\subsection{Phase 3 -- Engagement with local producers}

The first workshop attracted eleven actors from northeast Gothenburg, mainly producers and business developers. The aim of the workshop was to introduce business representatives to industrial symbiosis ideas and to start building symbiosis network.

A mapping showing potential collaboration between the participants and other known local stakeholders was prepared beforehand. This map was further developed in the workshop: existing collaborations, and the missing factors for the symbiosis network -- marketing, promoting food tourism to the area were identified.

It was concluded that there is a large demand for ecologically sound food, especially in the city centre. It was also determined that the actors from the consumer side, i.e. restaurants and grocery stores, would need to be involved in the IS formation. Ecological food certification and logistics were identified as key requirements. Visits were made to their business locations for small businesses that could not attend the workshop.

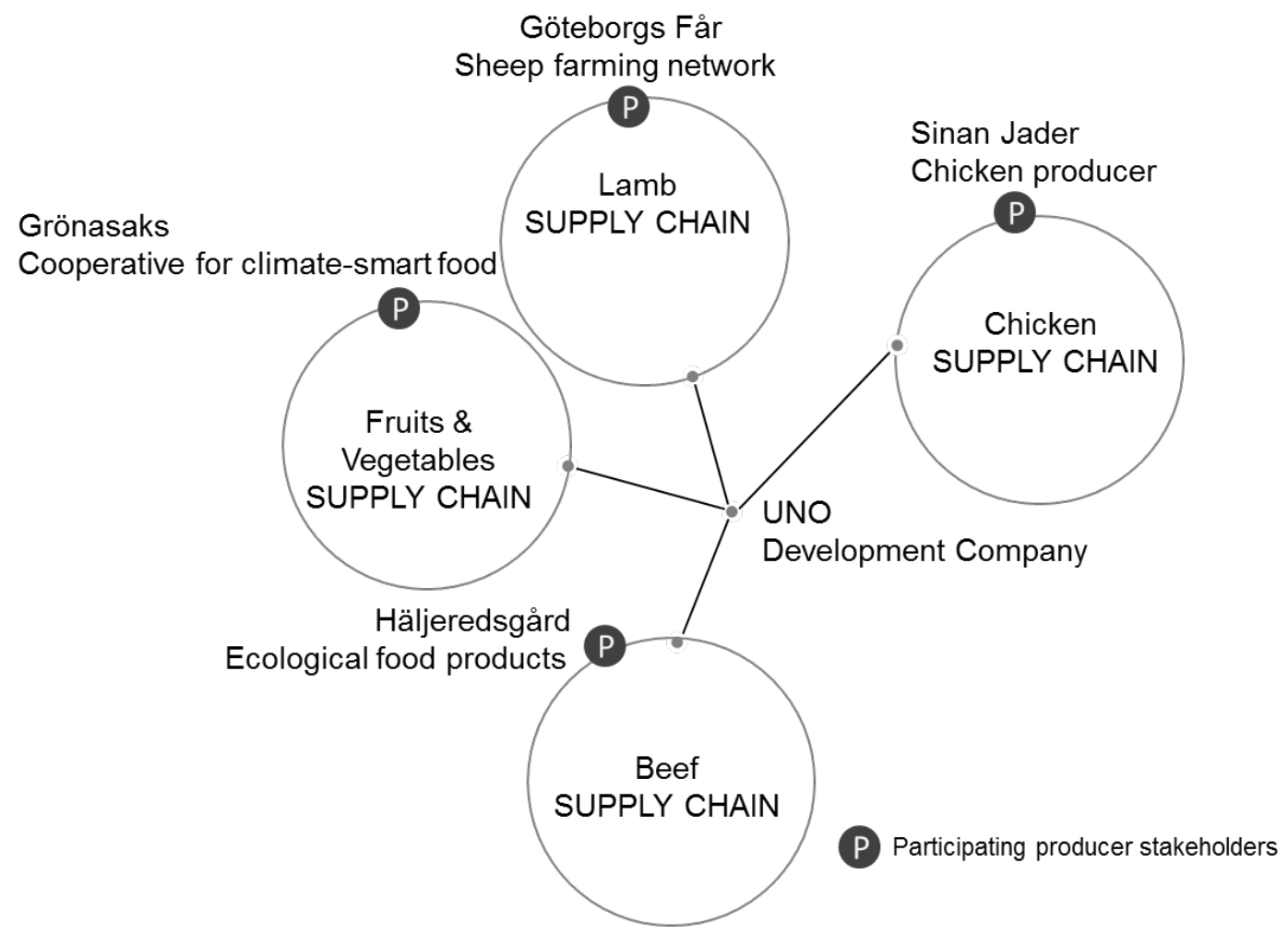

Figure 4. Main supply chains and key stakeholders for a food cluster in the northeast Gothenburg 


\subsection{Phase 4 -- Development of the food production cluster}

The first workshop developed a set of parameters for the food cluster. In particular, the final products should be climate-smart and locally produced, with an option for ecological certification. As defined in the focus phase, the supply chains include meat, fruits and vegetables.

To identify additional stakeholders and symbiosis links, the remaining stages of the value chain (Logistics, Consumption and EOL) need to be considered. The scenarios below explore three end markets (Consumption) and logistics for the locally produced food: public sector, retail market and restaurants. The post-consumer waste from food production (EOL) is managed by municipal service, having implications for supply chains as explained in the Outcome below.

The public sector in Sweden is responsible for social institutions such as schools, elderly care, and hospitals. It is the largest customer for many products, including food. It was found, however, that local food producers could experience challenges in supplying public establishments due to public procurement regulations.

The existing Swedish law on public procurement (LOU 2007:1091) does not allow public sector establishments to give preference to local production (Konkurrensverket, 2014). It requires a level tendering process when sourcing. As a result, the public sector purchases cheaper imported commodities that may have been produced under regulations less stringent than those in Sweden. Strict Swedish regulations include items such as farm animal welfare, and limits on fertilizer and pesticides application.

Amendments to the current public procurement law (SFS 2010:571) would introduce additional criteria, such as farm animal welfare, for broad sourcing. In this case, local producers will have a better chance for public sector sales. Certain municipalities, including Gothenburg, allow serving exclusively ecologically sound meat in public establishments. Having ecological certification, this increases local producers' chance to be selected as providers given their history of high quality production.

Another possibility is to supply products to retail markets such as shops, super markets or farmer markets hosting local producers. Customer inclination for locally produced and ecological sound food is perceived as an opportunity.

The UNO started a dialog with ICA Nära, a Swedish retail chain, in northeast Gothenburg regarding possible distribution of locally produced ecologically sound products. The main barrier to be considered is that ecologically sound products are more expensive.

Restaurants are suitable end-markets for locally produced food since they require smaller quantities of fresh and high quality products; they would like to work in close contact with producers to improve product flavor.

Distribution and logistics planning is important due to the small scale of both producers and end markets, and a potentially scattered network of customers. Given the identified challenges, it was 
decided to exclude the public sector as an end market at this stage of cluster development; the focus became food retailers and restaurants. New stakeholders, representing end markets and logistics, were identified (see Table 1).

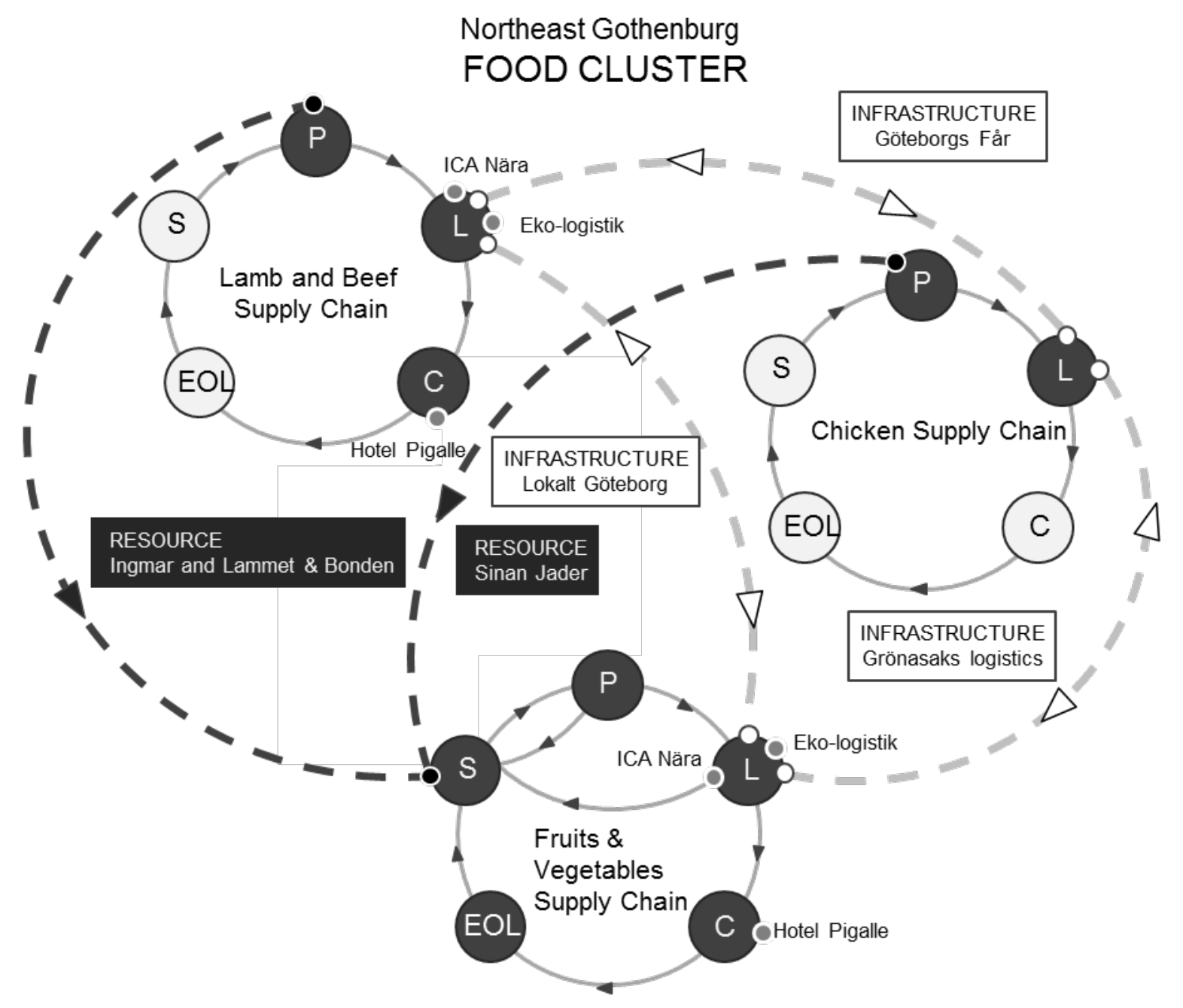

Figure 5. Industrial symbiosis cluster for northeast Gothenburg 


\subsection{Phase 5 -- Consolidation of the cluster}

The second workshop involved representatives from restaurants, a grocery store and a logistics company in addition to producers. The second facilitated workshop focused on developing concrete activities for strengthening planned and establishing new symbiosis links. A map of identified stakeholders and supply chains diagram guided the consolidated cluster outline. Discussions about sharing human resources, energy and waste treatment were postponed until after the initial symbiotic relationships were implemented.

Table 1 summarizes a list and description of the stakeholders involved in the planning and development of the northeast Gothenburg food cluster.

\subsection{The Outcome: an Industrial Symbiosis Design}

Using the facilitated IS development method, an industrial symbiosis cluster was formulated from the set of stakeholders described in Table 1.

The initial IS design serves as a baseline, with an option to enlarge the network with more participants. Table 1 lists both existing and planned stakeholders along with corresponding supply chain phases.

Figure 5 provides shows potential resource exchanges among the initial set of participating stakeholders. In the example, lamb and beef supply chains are merged together due to similar characteristics.

Resource exchange opportunities were identified, such as using wastes from chicken supply chain and the organic residue from biogas production at Häljeredsgård - a production stage of the beef supply chain -- as fertilizer for vegetable production.

In the vegetable supply chain, production stage waste can be used as fertilizer in sourcing -interaction using their own resources. A possible symbiosis was devised in the vegetable production chain by using waste heat and space from ICA Nära food retailer for setting up and running a greenhouse -- the logistics to sourcing link.

The external economies of scale can be created in the cluster by sharing the four supply chain infrastructures. Amongst these external partners includedthe distribution services of Eco-logistic and Grönsaks companies, the meat processing service of Göteborgs Får, marketing platform of Lokalt Göteborg, and retail and development of food tourism through Häljeredsgård.

For further cluster development, additional stakeholders representing the supply chain sourcing and consumption stages can be involved. EOL management of the post-consumer waste, the EOL of all supply chains in the food production cluster, is managed by the municipal service via food waste collection from homes and restaurants for anaerobic digestion to produce biogas. The residues from biogas production are planned to be used as fertilizer in the sourcing for vegetable production and for animal fodder production; this step closes the supply chain loop. 


\section{Discussion}

The suggested IS development facilitation method, based on combining IS with SSCM, contributes to $\mathrm{CE}$ development by closing the loops of resources. CE creates new business opportunities by more efficient use of resources through resource exchange and infrastructure sharing.

The method provides insights into SSCM since it was specifically developed for planning and design of closed loop supply chain systems. The method also advances IS with a standardized methodology to identify IS opportunities and facilitate exchanges.

Input-output matching principles for identifying IS opportunities, based on identifying complementary resource exchanges between different organizations, is applied (Grant et al. 2010). The communication method for input-output matching is used (e.g. via workshops), with three main types of actions: conversation, connection and co-creation (Paquin and Howard-Grenville, 2012).

Furthermore, we sought to expand IS to urban areas and communities in addition to the IS traditional focus on industrial eco-parks. The method has been applied to a case-study of cluster development in Gothenburg. A suitable cluster of food production was created based on the development goals for the area and on the local resources, including existing businesses, infrastructure, human and natural resources.

Several strengths, constraints and necessary adjustments are identified. For example, close contact between local producers and restaurants was found to be a strength. Producers are able to customize their products for the restaurants, which promotes lasting customer relationships. Also, flexibility of small-scale production allows for easier adaptation of the production processes, for example to ecologically sound production.

Limitations identified included retailer chains such as ICA require food products, especially vegetables, to conform to size and shape constraints. Limitation in production volumes of small size producers is a constraint for public sector supply and sales. Adjustments to the local cluster to make it more functional is needed. These adjustments include adding businesses within logistic services and meat processing. 
Table 1. Stakeholders in supply chain phases identified for northeast Gothenburg

\begin{tabular}{|c|c|c|c|c|}
\hline $\begin{array}{l}\text { Supply-chain } \\
\text { phase }\end{array}$ & $\begin{array}{l}\text { Stakeholder } \\
\text { type }\end{array}$ & Stakeholder & Status & Description \\
\hline \multirow{2}{*}{ Sourcing } & $\begin{array}{l}\text { Social } \\
\text { cooperatives }\end{array}$ & Häljeredsgård & Existing & $\begin{array}{l}\text { A cattle farm that produces biogas from the its } \\
\text { farm waste and can supply the resulting fertilizer }\end{array}$ \\
\hline & Retailers & ICA Nära & Existing & $\begin{array}{l}\text { A supermarket that can provide waste heat and } \\
\text { space for vegetable production }\end{array}$ \\
\hline \multirow[t]{5}{*}{ Production } & $\begin{array}{l}\text { Individual } \\
\text { farmers }\end{array}$ & Sinan Jader & Existing & Ecological poultry production \\
\hline & \multirow{2}{*}{$\begin{array}{l}\text { Farmers } \\
\text { network }\end{array}$} & Göteborgs Får & Planned & Sheep farming network \\
\hline & & Grönasaks & Existing & $\begin{array}{l}\text { Cooperative producing climate-smart food } \\
\text { products that also has an established retail and } \\
\text { logistics setup }\end{array}$ \\
\hline & $\begin{array}{l}\text { Social } \\
\text { cooperatives }\end{array}$ & Häljeredsgård & Existing & $\begin{array}{l}\text { Produces ecological food products (beef and milk), } \\
\text { produces biogas from the farm waste, exhibits as } \\
\text { an energy-farm }\end{array}$ \\
\hline & $\begin{array}{l}\text { Waste } \\
\text { exchangers }\end{array}$ & Göteborgs Får & Planned & Exchange of farm waste \\
\hline \multirow[t]{8}{*}{ Logistics } & \multirow[t]{3}{*}{$\begin{array}{l}\text { Logistics } \\
\text { services }\end{array}$} & Eko-logistik & Existing & $\begin{array}{l}\text { Formed by the organizations Lokalt Göteborg and } \\
\text { Utveckling Nordost, committed to the collective } \\
\text { logistics, distribution and finding the customers }\end{array}$ \\
\hline & & $\begin{array}{l}\text { Lokalt } \\
\text { Göteborg }\end{array}$ & Existing & Platform for farmers to advertise their products \\
\hline & & Grönasaks & Existing & Provides logistics services \\
\hline & $\begin{array}{l}\text { Infrastructures } \\
\text { providers }\end{array}$ & Göteborgs Får & Planned & Meat processing facility \\
\hline & \multirow[t]{4}{*}{ Retailers } & $\begin{array}{l}\text { Lärjeåns } \mathrm{K \& T} \\
\text { and } \\
\text { garden shops }\end{array}$ & Existing & Garden shop \\
\hline & & ICA Nära & Existing & Super market \\
\hline & & Grönasaks & Existing & Provides retail services \\
\hline & & $\begin{array}{l}\text { Farmer } \\
\text { markets }\end{array}$ & Existing & $\begin{array}{l}\text { Local markets set up by social cooperatives and } \\
\text { farmer groups }\end{array}$ \\
\hline \multirow[t]{4}{*}{ Consumption } & \multirow{3}{*}{$\begin{array}{l}\text { Private } \\
\text { consumers }\end{array}$} & Pigalle & Existing & Hotel with a restaurant \\
\hline & & Restaurants & Existing & $\begin{array}{l}\text { Cafés and restaurants that prepare meals from } \\
\text { ecological or locally-produced food products }\end{array}$ \\
\hline & & Households & Existing & \\
\hline & $\begin{array}{l}\text { Public } \\
\text { consumer }\end{array}$ & $\begin{array}{l}\text { Public sector } \\
\text { establishments }\end{array}$ & Existing & Schools, hospitals, elderly homes etc. \\
\hline End of Life & Municipal & $\begin{array}{l}\text { Waste/sewage } \\
\text { treatment } \\
\text { company }\end{array}$ & Existing & $\begin{array}{l}\text { Collection of food waste from homes and } \\
\text { restaurants for anaerobic digestion to produce } \\
\text { biogas, with residue being used as fertilizer. } \\
\text { Anaerobically digestion of sewage sludge. }\end{array}$ \\
\hline
\end{tabular}




\section{Lessons learned and practical recommendations}

The case study implementation of a facilitated IS and economic cluster development process has brought up several considerations for those seeking to apply the method.

Partnering with a connected local partner. Initially a good starting point for a project on economic cluster development is to find a local partner - a local government, NGO, business association, or a company -- interested in or tasked with the area's development. This partner requires knowledge of the area and is trusted by the local businesses. For the first meeting with a local partner we recommend preparing materials containing illustration of possible benefits for creating an economic cluster and industrial symbiosis. Using an existing or a hypothetical case and a brief description of the key principles and steps of the method should be included in the illustration.

Do your homework, prepare materials. Efficient workshops are a necessity. In order to maintain focus on finding collaboration opportunities and solutions for closing loops instead of spending time on introductions to businesses, the facilitator and the local partner - UNO in the case study should prepare background information.

Background information should include: (1) existing stakeholders; (2) types of used resources; (3) infrastructure and generated wastes; (4) existing examples of innovations in business models in the region area; and (5) initial propositions of possible symbiotic links.

Some of this information, especially general information about the types of business and their resource flows is available publicly. Information can be obtained from literature, the Internet or the local government business development unit. Additional information can be acquired from the local partner.

Utilize information for many purposes. Apart from serving as a starting point for the workshops, background information can also contributes in other ways. Building databases containing typical resource flows in different supply chains, possible resource exchanges, and examples of innovations in business models for future development projects.

Select a starting implementation point. Identifying a stage in the supply chain that will serve as a starting point for seeking symbiosis opportunities needs to be determined before the initiating workshop. This adds additional efficiency to the process and meeting. This selection is completed using the development objectives, existing industrial infrastructure, or suggestions by supply chain actors. For example, having production increase as an objective in our case study, meaning the starting stage was chosen to be production. The consumption stage could have been chosen in a case where cluster development is demand-driven by consumers, such as restaurants seeking specialty products, or Gothenburg municipality requiring organic meat due to the adopted policy of $100 \%$ organic meat served in public establishments.

Use partners to gather and disseminate information. Information about the initiating workshop is most efficiently disseminated by the local partner to potential participants. E-mail or letters, with suggestion to forward to other possibly relevant and interested businesses, was encouraged. Having a map of the region's industries during the workshops is helpful for locating supply chain elements. 
Existing and potential partners, infrastructure, and available underutilized resources --land or infrastructure, should be identifed. To save time, the description of cluster development methods and industrial symbiosis concept can be omitted during the workshops. Instead, an illustration of existing innovations within business models and resource management are useful for motivation.

Provide flexibility and support for smaller enterprises. Small and micro enterprises (SME) are important to local communities. These SME may not have resources to attend the workshops. They may provide input to cluster development through on-site discussion as exemplified in the case study. In some cases, attendance of SME in the workshops can be financially supported by local governments, NGOs or business associations. Additionally, companies with large or multiple byproduct streams may sponsor cluster development while seeking opportunities to reduce the cost of waste and byproduct disposal, valorize byproduct streams and improve their sustainability profile.

The post-facilitation process should be carefully planned. Based on the industrial symbiosis outline developed in this method, the cluster can be implemented with continued facilitation by the local partner, as in our case study, or by a consulting company providing facilitation on behalf of the agency driving area development -- local government, NGOs, business associations or companies. The post-workshop activities included raising seed funds that can help in accelerating initial cluster implementation based on the developed industrial symbiosis outline.

\section{Conclusion and future directions}

A method for planning and development of economic clusters based on industrial symbiosis and sustainable supply chain management concepts has been presented. It identifies opportunities for resource exchange, sharing of infrastructure and stakeholders collaboration in five phases: preparation; identification of the focus for potential cluster; engagement with stakeholders; synthesis of information and addition of new links to the cluster, and consolidation of supply chains and stakeholders in cluster.

The method contributes to sustainable development of local communities, strengthening them both economically and socially, around a circular economy perspective. In particular, the expected value from industrial symbiosis is more efficient use of local resources. This may lead to material and cost savings, improved security of supply, potential new businesses and employment opportunities, and reduced environmental pressures and impacts. The big picture behind developing the method was to provide business developers, NGOs and local authorities with a practical approach to urban and regional development and to promote a circular economy.

In partnership with municipal developer UNO, the method has been applied to a case of developing urban food production cluster in northeast part of Gothenburg, Sweden. Based on the development objectives, four key supply chains and potential resource and infrastructure sharing were identified. Working with the initial group of relevant stakeholders on formulating the cluster, symbiosis opportunities, additional stakeholders and missing infrastructure elements were jointly identified during the first workshop. 
The potential new end-markets for the cluster were investigated, and opportunities and challenges of industrial symbiosis implementation identified. Involving additional stakeholders, a more comprehensive and complete cluster outline was created during the second workshop. Along with the cluster outline, summarized in Figure 5 and Table 1, a set of recommendations for future development was provided to UNO for its implementation of the industrial symbiosis.

The recommendations include adding more partners (from Table 1) to the Logistics and Consumer stages of supply chains, applying more iterations of the method (central loop in Figure 3) to identify and add more partners and shared resources to the cluster, and creating new businesses to provide missing infrastructure (e.g. meat processing facility). Based on application of the method, UNO has obtained regional development funding from EU to implement the cluster as an integral part of North-East Gothenburg development.

We believe that this process can help urban planners and engineers with the necessary guidelines to initiate important transformations to their communities.

\section{Acknowledgements}

The authors acknowledge the European Institute of Innovation and Technology - Climate Knowledge Innovation Community (Climate-KIC) for its financial support in the IS-COM Industrial Symbiosis for Strong Communities project. We would also like to thank the project employee Madumita Sadagopan, and our partners Björn Wesling from Johanneberg Science Park, Stina Rydberg and Peter Carlsson from Hifab, and the Utveckling Nordost representatives, Dan Melander and Susan Runstén.

\section{References:}

Bathelt, H. (2005). Cluster relations in the media industry: exploring the 'distanced neighbour' paradox in Leipzig. Regional Studies 91, 105-127.

Battini, D. (2015). Special Issue on Closed Loop Supply Chain (CLSC): Economics, Modelling, Management and Control. Available at: http://www.journals.elsevier.com/international-journalof-production-economics/call-for-papers/special-issue-on-closed-loop-supply-chain-clsc/ [Accessed in August 2018].

Carter, C. R. and Rogers, D. S. (2008). A framework of sustainable supply chain management: moving toward new theory. International Journal of Physical Distribution \& Logistics Management, 38 (5), 360-387.

Cumbers, A. and Mackinnon, D. (2004). Introduction: Clusters in urban and regional development. Urban Studies 41, 959-969.

Deutz, P. and Gibbs, D. (2008). Industrial Ecology and Regional Development Eco-Industrial Development as Cluster Policy. Regional Studies 42 (10), 1313-1328.

Environmental and Climate Committee (2014). Climate programme for Gothenburg. Available at: 
http://international.goteborg.se/sites/international.goteborg.se/files/field_category_attachments/cl imate_programme_for_gothenburg.pdf [Accessed in May 2018].

EC, (2011). European Comission Roadmap to a Resource Efficient Europe. COM (2011) 571. Available at: http://eur-lex.europa.eu/legal-content/EN/TXT/?uri=CELEX:52011DC0571 [Accessed on October 2018].

Geng, J Sarkis, R Bleischwitz How to globalize the circular economy. Nature 565 (7738), 153.

Grant, G. B., Seager, T. P., Massard, G., \& Nies, L. (2010). Information and communication technology for industrial symbiosis. Journal of Industrial Ecology, 14(5), 740-753.

Guide, V. D. R., Harrison, T. P., \& Van Wassenhove, L. N. (2003). The challenge of closed-loop supply chains. Interfaces, 33(6), 3-6.

Jensen, P.D. (2016). The role of geospatial industrial diversity in the facilitation of regional industrial symbiosis. Resources, Conservation and Recycling, 107, 92-103.

Kalmykova Y., Sadagopan M. and Rosado L. 2018 Circular economy-From review of theories and practices to development of implementation tools. Resources, Conservation and Recycling 135, 190-201.

Konkurrensverket (2014). Konkurrensverket. Available at: http://www.konkurrensverket.se/ [Accessed in January 2018].

Leigh, M. and Li, X. (2015). Industrial ecology, industrial symbiosis and supply chain environmental sustainability: a case study of a large UK distributor. Journal of Cleaner Production, 106, 632-643

Liu, J., Feng, Y., Zhu, Q. and Sarkis, J. (2018). Green supply chain management and the circular economy: Reviewing theory for advancement of both fields. International Journal of Physical Distribution \& Logistics Management 48, 8, 794-817.

Lombardi, D. R. and Laybourn, P. (2012). Redefining industrial symbiosis. Journal of Industrial Ecology 16(1), 28-37.

Martin, R. and Sunley, P. (2003). Deconstructing clusters: chaotic concept or policy panacea? Journal of Economic Geography 3, 5-35.

Melander, D. (editor) (2013). Förstudien Stadslandet Göteborg. Available at: http://utvecklingnordost.se/Bilder/pdf/rapport\%20stadslandet.pdf [Accessed in May 2018].

Morgan, K. (2004). The exaggerated death of geography: learning, proximity and territorial innovation systems. Journal of Economic Geography 4, 3-21.

Paquin, R. L., and Howard - Grenville, J. (2012). The evolution of facilitated industrial symbiosis. Journal of industrial Ecology, 16(1), 83-93.

Patricio, J., Kalmykova, Y. and Rosado, L. (2019) Predicting detailed industrial waste generation - a necessary method to support planning and implementation of circular economy. Journal of Cleaner Production, under review. 
Sarkis, J. (2012) A boundaries and flows perspective of green supply chain management. Supply chain management: an international journal 17 (2), 202-216.

St. John, C. H. and Pouder, R.W. (2006). Technology clusters versus industry clusters: resources, networks, and regional advantages. Growth and Change 37, 141-171.

van Berkel, R. (2009). Comparability of industrial symbioses. Journal of Industrial Ecology 13(4), 483-486.

UNEP (2012). Responsible Resource Management for a Sustainable World: Findings from the International Resource Panel. Available at:

http://www.unep.org/resourcepanel/Portals/50244/publications/SYNOPSIS\%20Final\%20compre ssed.pdf [Accessed in June 2018].

UN, (2014) United Nations. World Urbanization Prospects. Available at:

https://esa.un.org/unpd/wup/Publications/Files/WUP2014-Highlights.pdf [Accessed in June 2018] 